\title{
Kajian Tentang Komunitas Virtual: Kesempatan dan Tantangan Kajian di Bidang Ilmu Komunikasi
}

\author{
Anastasia Yuni Widyaningrum \\ Universitas Katolik Widya Mandala Surabaya \\ Alamat: J1. Dinoyo 42-44 Surabaya-60265, Indonesia \\ E-mail: anastasia_widya@ukwms.ac.id

\section{Study of Virtual Communities: Opportunities and Challenges in Communication Studies}

\begin{abstract}
This article is a literature review on virtual communities from phenomena, theories to the application of methods and research opportunities and challenges. The Internet removes the constraints of space and time and allows individuals to be connected from multiple locations and across identities. Using Sociological thinking about gemeinschaft and gesselschaft to explain the existence of communities in the internet era called virtual communities, this literature review seeks to apply them in the study of Communication Science. Various studies on virtual communities have been driven by rapid development of social media which enable long distance communication among people living in the different places all over the world.
\end{abstract}

Keywords: virtual community; cyberspace; community; ICTs.

\begin{abstract}
ABSTRAK
Artikel ini merupakan kajian literatur mengenai komunitas virtual dari fenomena, teori hingga aplikasi metode dan peluang serta tantangan penelitian. Internet meniadakan kendala ruang dan waktu dan memungkinkan keterhubungan individu dari berbagai lokasi dan lintas identitas. Menggunakan pemikiran sosiologi tentang gemeinschaft dan gesselschaft untuk menjelaskan keberadaan komunitas di era internet yang disebut dengan komunitas virtual, kajian literatur ini berusaha untuk menerapkannya dalam kajian ilmu komunikasi. Berbagai kajian mengenai komunitas virtual muncul dikarenakan salah satunya perkembangan media sosial yang memungkinkan individu yang tersebar secara fisik berinteraksi di dunia maya.
\end{abstract}

Kata kunci: komunitas virtual; ruang siber; komunitas; teknologi infomasi komunikasi. 


\section{LATAR BELAKANG}

Artikel ini memaparkan kontribusi penting kajian Ilmu komunikasi dalam memahami dinamika komunitas yang dimediasi oleh internet. Internet mengubah lanskap kajian berbagai disiplin ilmu tak terkecuali ilmu komunikasi. Perkembangan teknologi informasi dan komunikasi (TIK) komputasi broadband, nirkabel, dan seluler-dikombinasikan dengan media sosial seperti blogging, microblogging, dan jejaring sosial menjadi semakin terintegrasi dengan kehidupan sehari-hari (Haythornthwaite \& Kendall, 2010). Menjadikan kehidupan sehari-hari dalam dekade terakhir ini dipengarui oleh konvergensi media, mediasi, remediasi identitas dan juga minat yang semakin meningkat karena ketersediaan data penyimpanan secara besar dalam teknologi cloud (Markham, 2018, p. 1130). Hal tersebut telah diramalkan oleh ilmuwan komputer dan programmer Murray Turof dan sosiolog Roxanne Starr Hiltz dalam buku Network Nation (terbit pertama 1978), dimana web bersifat sosial sejak awalnya (Kozinets, 2015).

Saat ini, kita hidup dalam masyarakat digital dalam arti kita berada di era di mana kehidupan, hubungan manusia satu dengan yang lain, budaya, dan sosialitas kita digitalisasi, dan terpengaruh secara keseluruhan dengan proses digital, (Lindgren, 2017). Bentuk komunikasi yang dimediasi internet dapat ditemui melalui email dan mailing list, blog, media sosial, instant messaging (Whatsapp, Telegram, Line, dII). Di era awal tahun 2000an mailing list Yahoo! Groups sangat terkenal dan banyak digunakan untuk berdiskusi. Yahoo! Groups adalah platform email yang meluaskan fitur dengan grup secara online ini merupakan pionir perbincangan kelompok secara virtual. Yahoo! Groups didirikan pada tahun 2001 dan sejak itu peluncurannya telah menarik jutaan pengguna dari seluruh dunia dunia, (Agostini \& Mechant, 2019). Meskipun sejarah panjang dalam menghubungkan pengguna di Internet, Yahoo! Groups tidak banyak berubah dalam penampilannya dan fungsi. Pada dasarnya, Yahoo! Groups adalah kombinasi dari milis berbasis web dengan profil pengguna dasar dan fasilitas pengarsipan (Choi et al., 2019).

Forum diskusi berbasis internet misalnya kaskus. Forum diskusi online melalui aplikasi seperti Zoom (2012), Googlemeet (2017, merupakan reinkarnasi dari google hangouts yang dibuat pada tahun 2011), Webex, Microsoft Teams (2017), dll. Teknologi yang memediasi pertemuan langsung ini tidak terlalu baru, pada tahun 2003 telah dikembangkan aplikasi Skype, aplikasi percakapan telepon yang berbasis internet, tujuan awalnya untuk mereduksi biaya percakapan internasional pada waktu itu. Meski teknologi ini tidaklah terlalu baru namun penggunaan yang masif terasa di saat keterbatasan fisik karena situasi pandemi yang bersifat global.

Dari fenomena di atas dapat dilihat bahwa dinamika kehidupan sosial juga terdigitalisasi dan seolah olah di dunia ada dua kehidupan yaitu kehidupan riil-fisik-nyata dan kehidupan tidak riil-abstrak-maya yang dimediasi oleh internet. Berbagai produk turunan dari internet memberi ruang bagi kehidupan maya untuk berkembang dan bahkan interaksi yang termediasi oleh internet kemudian membentuk komunitas-komunitas baru di ruang digital. Seperti fitur pembentukan kelompok di instant messaging Whatsapp dan Facebook, terbentuknya komunitas daring dalam blog dan media sosial (Twitter, Facebook, Instagram, YouTube dll). Berbagai topik disirkulasikan melalui konten digital yang membangun komunitas online yang seringkali tidak disadari, meski di banyak akun disengaja untuk menggalang komentar dan juga interest netizen.

Kehadiran teknologi dalam masyarakat menjadikan budaya dan teknologi kemudian tidak berdiri sendiri atau kemudian saling terasing, namun adaptasi budaya pada teknologi bergerak cair, gampang berubah mengikuti bentuk dan juga transformatif (Kozinets, 2015, pp. 8-11). Lebih lanjut dijelaskan Kozinet, bahwa pertemuan individu yang dimediasi oleh teknologi komunikasi dalam hal ini website sekaligus mengingatkan bahwa individu tersebut pun datang dari dari segala keragaman, heterogenitas, ketidakpastian, dll. Nilai dan institusi komunitas budaya kemudian bergantung pada kepatuhan individu dalam berinteraksi dimana ada keberlanjutan, kebermaknaan, pemeliharaan dan juga nilai.

World Wide Web (www) membuka peluang individu mulai berkomunikasi, bersosialisasi, berkumpul membentuk komunitas, dan bahkan berorganisasi tanpa ada kendala ruang dan waktu. Kontribusi komputer dan perkembangan teknologi komunikasi menjadikan bentuk komunikasi ini menjadi yang termurah, paling nyaman dan merupakan opsi yang berpotensi paling kuat bagi individu yang tersebar secara geografis untuk dapat bertukar pendapat dan informasi (Hitz \& Turoff, 1993). Perkembangan teknologi komunikasi yang masif ini mendorong ilmuwan sosial dari berbagai disiplin mempelajari berbagai kemungkinan dari digitalisasi dan mediasi di masyarakat kontemporer (Waisbord, 2019).

Bagi Waisbord (2019), perkembangan digital membuat berbagai disiplin ilmu mengadopsi kata digital dalam kajiannya, termasuk ilmu komunikasi. IImuwan dari berbagai bidang ilmu melakukan penelitian bersama berkaitan dengan parenting, kebijakan, romance and religion, migrasi, pengawasan, pornografi dan kekerasan, pekerjaan dan waktu luang. Secara tradisional, media digital dipelajari oleh ilmuwan komunikasi berkaitan dengan informasi dan makna jaringan yang berkaitan dengan interpersonal dan berbicara di depan umum. Ilmu politik mempelajari berbagai platform digitaliasi dari politik. Ahli psikologi mempelajari medium berkaitan 
dengan psikis manusia, kemampuan bersosialisasi, emosi, perasaan, rasionalitas, dan juga perilaku. Ahli geografi tertarik pada kajian tentang ruang dalam dunia digital. Ahli komputer mempelajari karakteristik dan dinamika jaringan dan algoritma dalam medium digital. Studi tentang digital juga menjadi pusat perhatian pada pendidikan, manajemen bisnis, interaksi keluarga, dan kehidupan sosial, relationship dan pernikahan, propaganda dan diplomasi. Selanjutnya IImu Komunikasi dapat terlibat dalam kajian digital ini, dalam kaitannya dengan komunitas yang berkembang di media digital.

Medium digital tidak lagi dipahami sebagai wadah atau medium yang statis, namun disebut secara sosial dikonstruksikan, dibentuk dan dibagi dan melibatkan kajian tentang komunikasi manusia (McMullan, 2020). Ariel Heryanto (2015) menyebutkan bahwa teknologi adalah bagian dari legitimasi manusia moderen, dimana komoditas moderen dikonsumsi untuk pemenuhan kesenangan dan menjalani kehidupan yang sedang tren saat ini. Dari yang disampaikan tersebut jelas bahwa manusia moderen dan teknologi tak bisa dipisahkan. Dijelaskan pula bahwa kaum muda kelas menengah perkotaan bahkan sibuk melakukan negosiasi (memperbaiki, merumuskan ulang, menegaskan ulang) identitas sosial mereka. Manusia hidup dalam dunia tanda dimana teknologi digital memberikan ruang.

Penelitian tentang media dalam komunikasi semakin meluas dengan mulai diterimanya kajian-kajian media yang bukan hasil dari produksi industri, namun media adalah praktik (practice) dalam kehidupan sehari hari (Couldry, 2004). Media dalam konteks lama adalah medium dan teks dari hasil sebuah industri media, namun kehadiran internet dan perkembangan studi kajian media yang juga mempunyai singgungan dengan studi kajian budaya (cultural studies) memberikan pandangan baru apa yang disebut sebagai media/teks. Kehadiran teknologi internet ini menurut Couldry (2004) menjadi perbincangan antara disiplin ilmu Sosiologi, Antropologi dan Komunikasi. Ketiganya tertarik mempelajari masyarakat beserta perubahan-perubahan masyarakat sesuai perkembangan kehidupan sosial.

Tercipta sebagai makhluk sosial, individu selalu berusaha terhubung dengan individu lain. Daniel Bell (Bell, 1999) terbit pertama kali tahun 1973 menjelaskan keterhubungan individu ini tidak begitu saja terjadi, namun melalui berbagai sarana prasarana. Berdasarkan sejarah manusia terhubung dengan tiga jenis yaitu infrastruktur, simpul-simpul (nodes) dan melalui perdagangan atau transaksi. Infrastruktur meliputi sungai, jalan, kanal, rel kereta api, jalan bebas hambatan dan pesawat. Simpul-simpul terdiri dari system energy yang berupa hydropower, peralatan elektronik, minyak, gas dsb. Sedangkan yang ketiga adalah komunikasi dalam bentuk kantor pos, telegraph, telephone, radio, dan sekarang segala sesuatu yang dihubungkan dengan satellite.

Keterhubungan individu dalam masyarakat erat kaitannya dengan fase perubahan masyarakat di dunia dari masyarakat agraris, masyarakat industri, menuju masyarakat informasi (Bell, 1999). Sedangkan menurut Castell (2010) membahas perubahan konstelasi masyarakat karena kehadiran internet, tidak sekedar cara-cara komunikasi dan medium yang digunakan namun mengubah cara-cara lama dalam interaksi. Mulai dari pemerintahan, politik, komunikasi, budaya, komunitas, dll. Castell membahas budaya adalah konsep yang abstrak dan maya atau virtual dimana integrasi komunikasi dengan elektronik mengantarkan masyarakat ke jaringan yang interaktif dan meninggalkan budaya massa yang dibawa oleh teknologi komunikasi lama, yaitu media massa baik cetak maupun elektronik.

Internet mengubah konstelasi masyarakat, tidak sekedar cara-cara komunikasi dan medium yang digunakan, namun mengubah cara-cara lama dalam interaksi. Mulai dari pemerintahan, politik, komunikasi, budaya, komunitas, dll. Integrasi komunikasi dengan elektronik mengantarkan masyarakat ke jaringan yang interaktif dan meninggalkan budaya massa yang dibawa oleh teknologi komunikasi lama, yaitu media massa baik cetak maupun elektronik (Castell, 2010). Dalam konteks ini, internet terlihat secara fundamental telah mengubah praktik-praktik berkomunikasi dalam masyarakat.

Internet menghasilkan interactive society seperti yang dijelaskan oleh Castell (2010). Bentuk-bentuk teknologi informasi terintegrasi dalam jaringan global dimana computer-mediated communication mendorong terbentuknya virtual communities. Selanjutnya, dunia yang terkoneksi ini ditempatkan dalam karakteristik tertentu dengan tranformasi pengalaman manusia akan ruang dan waktu. Komunikasi yang dimediasi oleh internet sebagai tantangan untuk mencari makna baru. Komunikasi yang dimediasi oleh internet semakin menjangkau banyak pengguna dibandingkan komunikasi yang dimediasi oleh komputer. Di era internet kemudian muncul berbagai komunitas baru, komunitas virtual, mendorong individu semakin terbuka atau bahkan memutuskan individu dari masyarakat yang merupakan dunia empiric yang nyata.

Internet merupakan integrasi teks yang berupa tulisan, gambar dan suara dalam satu sistem, interaksi dari berbagi sudut pandang dalam waktu bersamaan namun juga bisa tunda dalam jaringan global, dalam kondisi akses terbuka dan terjangkau secara mendasar telah mengubah karakter komunikasi (Castells, 2010). Dalam situasi tersebut kita tidak lagi menggambarkan realitas, namun bahasa mengungkapnya. Media adalah bentuk metafora dari masyarakat dimana metafora tersebut dibentuk melalui konten tentang masyarakat. Dalam arti 
lain, masyarakat yang kita lihat di media bukanlah masyarakat yang sesungguhnya namun ia adalah bentuk perumpamaan situasi riil masyarakat (Castells, 2010).

Berdasarkan data dari WeAreSocial (Kemp, 2020) dibandingkan dengan tahun 2019 pengguna media sosial meningkat $49 \%$ per hari , Indonesia menduduki peringkat keempat setelah Filipina-Colombia-Brazil-Nigeria dengan rata-rata 3 jam 26 menit sementara rata-rata dunia adalah 2 jam 24 menit. Secara global platform Facebook di urutan paling atas dari media sosial yang digunakan secara global, kemudian menyusul di bawahnya Instagram, LinkedIn, Snapchat, Twitter, Pinterest, YouTube, Wechat, QQ, Qzone, Sina Weibo, Reddit.

Facebook menyediakan fitur untuk berinteraksi dalam bentuk percakapan secara personal dengan fitur pesan Im messanger. Interaksi percakapan terbuka disediakan dalam fitur "apa yang ada dalam pikiranmu? atau what's on your mind" yang kemudian meluas dalam komentar dan balasan komentar atas unggahan tersebut. Termasuk juga keterlibatan dalam pembicaraan melalui fitur "like atau menyukai dengan berbagai emoticon", "share atau bagikan" dan "tag atau tandai". Selain fitur utama interaksi komunikasi, Facebook juga menyediakan fitur grup, fitur marketplace, dan juga game, dan fitur lainnya. Facebook menjadi menarik jika semakin banyak teman yang diundang untuk dapat menjalin pertemanan di Facebook. Melalui menambahkan teman, pengguna Facebook akan semakin terhubung dan membuka peluang untuk berbagi yang merupakan inti dari Facebook, (Dalsgaard, 2016). Komunitas virtual juga yang terbentuk di Facebook misalnya akun grup "Info Lantas Sidoarjo", yang isinya berbagai informasi terutama tentang kejadian-kejadian di lalu lintas Kabupaten Sidoarjo. Grup ini dibentuk oleh individu yang merasakan perlunya berbagi infomasi sesama pengguna jalan. Informasi situasi jalanan tidak mudah untuk ditemukan dari media manapun. Informasi lokal sangat diperlukan oleh warga lokal.

Instagram yang pada awalnya digunakan oleh individu secara pribadi untuk berbagi momen melalui foto. Fitur Instagram yang menyediakan penyuntingan foto secara instant menjadi perhatian anak muda setelah generasi facebook yang dianggap sudah terlalu usang bagi orang muda. Warga Instagram juga bersatu-padu dalam sebuah aksi dukungan bagi atlit Indonesia yang digagalkan berlaga di All England.

Twitterland adalah sebutan bagi individu yang bergabung di Twitter, setiap hari muncul tanda tagar untuk memberi komentar mengenai berbagai kasus yang merebak secara daring. Para netizen, memberi pandangan, berbagai informasi tambahan, melakukan retweet sebagai bentuk dukungan agar informasi semakin tersebar luas. Dalam tahun 2020 menurut catatan yang dirilis oleh tim Twitter Indonesia keberagaman issue mulai dari politik, kesehatan, lingkungan sosial, olah raga hingga budaya populer.

Demikian juga berkembangnya forum diskusi melalui internet juga semakin beragam dan terbuka untuk bisa diikuti oleh masyarakat. Informasi keikutsertaan dibagikan secara berantai melalui jejaring percakapan dan juga media sosial. Topik diskusi juga beragam mulai dari tataran akademik, kebijakan dan implementasi, hingga persoalan lokalitas dan bahkan hobi.

Termasuk juga media mainstream yang membuat akun di media sosial, sehingga memungkinkan audience melakukan interaksi berupa komentar melalui fitur komentar pada media sosial. Media cetak dan elektronik meluaskan keterhubungan dengan audience dengan membuat website dan membuat akun di media sosial sebagai tempat membagikan link web berita. Salah satu contohnya adalah Radio Suara Surabaya dengan kanal FM 100.00 mengudara di Surabaya dan sekitarnya. Melalui media sosial, Radio Surabaya tidak jarang menggalang simpati dan dukungan para netijen serta ajakan untuk terlibat pembicaraan dalam berbagai isu politik, budaya, tata kelola kota, lalu lintas serta isu sosial. Tidak jarang pula para netizen seolah-olah bertindak sebagai jurnalist warga dan memberikan informasi penting bagi kehidupan bersama di Surabaya. Tak kurang isu orang hilang, pencurian kedaraan, jalan berlubang, hingga persoalan politik menjadi arena diskusi warga secara terbuka di akun media sosial Radio Suara Surabaya.

Komunikasi yang berlangsung berulang kali melalui platform digital menghasilkan sesuatu yang lebih dari sekedar hubungan sosial, namun melibatkan perasaan memiliki bersama atau persahabatan. Komunikasi mengubah bentuk sosial ini menjadi komunitas, (Fuchs, 2014c). Komunikasi berjejaring ini pada akhirnya membentuk berbagai komunitas virtual. Komunitas virtual adalah kumpulan individu dan / atau mitra bisnis (sehubungan dengan satu atau lebih dari kelompok organik masyarakat), yang berinteraksi karena kepentingan bersama (atau saling melengkapi) dan di mana interaksi tersebut menggunakan bahasa secara umum dan akhirnya kemungkinan munculnya paralanguage umum, dalam kelompok ini ada protokol atau norma bersama sebagai petunjuk yang disepakati bersama. Komunitas ini terwujud setidaknya sebagian dalam ruang bersama digital dan didukung dan / atau dimediasi oleh Internet atau sistem TIK lainnya (yang dapat sinkron, asinkron, atau hibrid) (Agostini \& Mechant, 2019).

Transformasi sosial ini tidak serta merta terjadi namun terjadi secara bertahap, dan masih terus berkembang hingga saat ini (Lindgren, 2017). Komunitas telah ada selama manusia, dan sepanjang sejarah. Teknologi (kereta api, gelombang radio, pesawat terbang, jaringan seluler, dll.) dan media (alfabet, kertas, kaset 
video, televisi, dll.) telah memfasilitasi pembuatan dan pemeliharaan komunitas. Evolusi internet dan media sosial tidak terkecuali. Media online yang berkembang memungkinkan interkonektivitas manusia terus berlanjut dan memunginkan untuk membangun dan memelihara simbol bersama, menyampaikan kisah dan sejarah bersama, dll.

Revolusi digital merupakan hal penting dalam peradaban manusia bahkan diakui merupakan titik balik yang monumental dalam studi komunikasi (Waisbord, 2019, p. 35). Menurut Waisbord, internet bukan hanya kasus lain dari babak baru inovasi teknologi yang membuka arah penelitian dan menambahkan lapisan analitis, namun mempunyai implikasi mengubah studi Komunikasi dan mendorong lebih jauh dari segi teori, ontologi, epistemologi, dan axiologi. Berikut ini adalah bebrapa contoh kajian yang berkaitan dengan komunitas virtual.

Penelitian mengenai interaksi komunikasi dalam komunitas virtual, misalnya berkaitan dengan proses pembelajaran dengan memanfaatkan Facebook pada sekolah tingkat atas di Hongkong (K. Wong et al., 2011). Menggunakan teori Community of Practices (COP) dengan tiga syarat utama, yaitu (1) situs web dalam hal ini adalah Facebook, (2) komunitas, dan (3) praktik. Hasil penelitian menunjukkan bahwa Web 2.0 mampu untuk mempromosikan kemampuan siswa dan membantu dalam membuat, berkolaborasi, serta berbagi konten. Dalam hal ini, Facebook dapat dipandang sebagai lambang Web 2.0 yang memfasilitasi, berbagi, interaksi dan kolaborasi di antara penggunanya Selain popularitasnya, Facebook mendukung pendekatan pembelajaran yang inovatif, memotivasi partisipasi siswa, menyajikan materi multimedia dan memungkinkan siswa untuk berbagi sumber daya. Siswa dapat berinteraksi dalam kelompok kecil atau bahkan seluruh kelas dapat berkomunikasi dengan pesan teks dalam mode asynchronous dan synchronous. Peluncuran fitur konferensi video Facebook dalam waktu dekat memiliki potensi besar untuk mengajar dan belajar. Penelitian Wong ini menunjukkan cara kerja fitur media sosial bisa digunakan secara positif untuk kepentingan praktis dan profesional untuk meningkatkan mekanisme pembelajaran.

Kajian partisipasi aktor sosial, interaksi dan identitas dalam komunitas virtual diteliti konteks masyarakat Spanyol (Reyes, 2019). Identitas online dibangun secara interaksional, juga diskursif dan hal ini merupakan proses mendefinisikan perbedaan dalam kelompok, menggambarkan sifat jarak dalam online. Penelitian ini berdasarkan kajian Citizen Sociolinguistics, yaitu cara individu menggunakan bahasa dan menghasilkan pemetaan komentar dalam komunikasi digital. Melalui analisis 500 komentar yang diposting oleh pembaca di situs surat kabar El País, sebagai tanggapan atas artikel yang mengumumkan reformasi ortografi Spanyol yang baru. Hasilnya adalah identitas dan hierarki dalam komunikasi digital sebagai hasil sosial budaya dari interaksi linguistik.

Penelitian tentang komunitas virtual dan kaitannya dengan budaya misalnya dalam konteks masyarakat Republik Serbia (Baltezarevic et al., 2019) Menyelidiki pengaruh budaya pada proses menjalin relasi dalam komunitas virtual. Munculnya internet dan berbagai bentuk komunitas virtual telah menimbulkan dampak ruang sosial baru pada individu sebagai bentuk alternatif bersosialisasi. Secara virtual komunitas, 'persahabatan' baru dengan mudah diterima; Pendekatan kuantitatif dengan metode survei. bahwa terdapat hubungan moderat dan positif antara sikap tentang penerimaan orang yang tidak dikenal dalam komunitas virtual dan sikap tentang perubahan identitas budaya menyelidiki dinamika virtual komunitas dengan mengacu pada dampak pada identitas budaya dalam konteks dan metode yang berbeda.

Salah satu penelitian menggunakan metode digital etnography membahas pola komunikasi dalam jaringan crytocurrency (Tjahyana, 2021). Studi ini mengobservasi Twitter yang membahas mengenai Dogecoin dengan teknik mengambilan data dengan alat Brand24 dan Netlytic. Hasil penelitian menunjukkan pola komunikasi di twitter berjalan satu arah. Meski begitu komunitas berfungsi sebagai dukungan psikologis saat anggota mengalami kerugian saat trading.

Dalam konteks Indonesia, penelitian yang sudah dilakukan tentang komunitas virtual berkaitan solidaritas yang digalang melalui media sosial (Maryani, 2018). Melalui studi kasus pada kelompok Ika (Indonesia Untuk Kemanusiaan) penelitian ini lebih memfokuskan cara medium digital dapat digunakan untuk menggalang solidaritas lintas batas. Data dikumpulkan melalui wawancara dengan pengurus komunitas tersebut. Indonesia Dalam rangka menjunjung kemanusiaan tidak berfokus menggalang solidaritas melalui medium digital, namun aktifitas secara offline mereka lakukan. Hasil penelitian menunjukkan, bahwa melalui medium digital dan karakteristiknya maka aksi solidaritas jauh lebih cepat daripada offline. Meskipun begitu, pendekatan secara personal juga penting untuk menguatkan kepercayaan dan kredibilitas. Penelitian ini fokus pada mekanisme medium digital untuk menggalang solidaritas.

Meskipun teknologi informasi komunikasi dan kajian berkembang lebih ke persoalan teknologi deterministik, namun bagi Servaes dan Hyong (2017) teknologi jaringan adalah kunci konsepsi agensi dan perubahan yang berakar pada praktik sosio-teknis dalam komunitas virtual. Perbedaan dan tumpang tindih antara wacana dan praktik para aktor yang menganggap diri mereka bertentangan secara ideologis, namun 
semuanya diinvestasikan dalam memobilisasi Teknologi Informasi dan Komunikasi (TIK) untuk perubahan sosial. Fokus pada pekerjaan para aktivis, seperti gerakan anti perubahan globalisasi, dan pada sektor pembangunan yang berinvestasi pada akses teknologi dan pelatihan keterampilan untuk memprovokasi perubahan sosial sebagai cara untuk mengentaskan keterbelakangan, ketidaksetaraan sosial, dan kemiskinan.

\section{METODE}

Artikel ini menggunakan paradigma konstruktivisme dengan metode tinjauan literatur berkaitan dengan konsep dan hasil penelitian mengenai komunitas virtual dan konsep-konsep yang berdekatan dalam mendukung penjelasan dalam kajian IImu Komunikasi. Dalam merumuskan kajian literatur menggunakan pendekatan kualitatif dengan metode meta-narasi, yaitu tinjauan sistematis yang mengulas topik-topik baru dari konsep yang berbeda dan dipelajari oleh berbagai kelompok peneliti (G. Wong et al., 2013). Tinjauan literatur penting bagi penelitian sebagai kerangka berpikir. Fungsi dari tinjauan literatur untuk memetakan perkembangan pengetahuan serta membuat panduan dalam praktik penelitian, serta memberikan bukti bukti empirik yang bermanfaat bagi perkembangan ide-ide baru akan penelitian berikutnya (Snyder, 2019).

\section{HASIL DAN DISKUSI}

\section{Konsep Dasar Komunitas Virtual}

Konsep komunitas berangkat dari pemikiran Sosiolog Jerman Ferdinand Tönnies (1855-1936) pada tahun 1887 tentang Gemeinschaft dan Gesellschaft, (Agostini \& Mechant, 2019; Brint, 2001). Gemeinschaft dan Gesellschaft merupakan dikotomi antara hubungan komunal dan asosiasi berbasis kepentingan (Brint, 2001). Terobosan Tonnies adalah melepaskan diri dari perdebatan abadi tentang keunggulan cara hidup desa dan perkotaan; untuk melepaskan cara hidup ini secara konseptual dari konteks spasial yang mereka kenal; dan untuk mencoba mengidentifikasi fitur dominan dan kualitas dari setiap cara hidup. Berikut tabel perbedaan antara Gemeinschaft (masyarakat komunal atau paguyuban) dan Gesellschaft (masyarakat asosiasi/patembayan) oleh Tonnies, berdasarkan penjabaran dari Brint (2001).

Table 1 Perbedaan Gemeinschaft dan Geselschaft .

\begin{tabular}{|c|c|}
\hline Gemeinschaft & Gesellschaft \\
\hline Terkait dengan cara hidup yang umum & Cara hidup yang berbeda-beda \\
\hline Keyakinan pada umumnya sama & Keyakinan pada umumnya berbeda \\
\hline $\begin{array}{l}\text { Konsentrasi pada keeratan dan frekuensi } \\
\text { interaksi yang sering. }\end{array}$ & $\begin{array}{l}\text { dengan ikatan yang terpencar dan interaksi } \\
\text { yang jarang }\end{array}$ \\
\hline Jumlah anggotanya sedikit & $\begin{array}{l}\text { Jumlah anggotanya banyak dan tak } \\
\text { terhitung }\end{array}$ \\
\hline Ada jarak dengan pusat kekuasaan & Ada kedekatan dengan pusat kekuasaan \\
\hline Penuh keakraban & $\begin{array}{l}\text { dengan aturan untuk mengatasi } \\
\text { ketidakpercayaan }\end{array}$ \\
\hline Ada kesinambungan & temporal \\
\hline Ada ikatan emosional & Ada aturan aturan \\
\hline
\end{tabular}

Sumber: Olahan penulis bersarkan penjelasan Brint (2011)

Dari pemikiran Ferdinan Tonnies tersebut terjadi pergeseran dari sebuah komunitas karena perkembangan teknologi komunikasi. Perubahan radikal dalam ranah komunikasi, berasal dari revolusi teknologi komunikasi. Internet menggeser sistem jaringan komunikasi dari media massa tradisional dan merubah secara fundamental menjadi virtual (Castells, 2010). Kehadiran internet bahkan disebut sebagai era mesin kedua setelah revolusi industri dan mengubah bagaimana manusia berkomunikasi (Gallardo, 2019).

Internet dan media sosial secara dramatis mengubah relasi dan interaksi individu. Internet dan media sosial menawarkan peluang baru untuk orang yang yang terbatas secara geografis untuk membentuk hubungan kolaborasi dan ikatan. Saat online, seseorang tidak perlu melihat persoalan jarak fisik, menjangkau satu sama lain dengan berbagai cara untuk membuat, atau berafiliasi dengan, berbagai grup online (Lindgren, 2017). Ruang sosial di Web, yang dibangun di atas tradisi perintis komunitas virtual pada 1980-an membentuk beragam komunitas virtual. Pertumbuhan media berjejaring selain email telah meningkatkan berbagai bentuk komunitas virtual (Castells, 2010). 
Howard Rheingold (1994), dalam buku perintisnya, "Virtual Community", sebagai awalan perdebatan tentang lahirnya bentuk komunitas baru, menyatukan orang secara online seputar nilai dan minat bersama. Selanjutnya, berdasarkan pengalamannya sendiri dengan WELL (Whole Earth 'Lectronic Link - salah satu sistem buletin yang paling awal), sebuah jaringan komputer kerjasama di kawasan Teluk San Francisco, gagasannya bahwa komunitas yang dibangun secara online dapat berkembang, menjadi pertemuan fisik, pesta persahabatan, dan dukungan materi untuk anggota komunitas virtual mereka. Komunitas virtual, sejalan dengan argumen Rheingold, secara umum dipahami sebagai jaringan elektronik yang ditentukan sendiri dari komunikasi interaktif terorganisir seputar minat atau tujuan bersama, meskipun terkadang komunikasi menjadi tujuan itu sendiri. Komunitas seperti itu mungkin saja relatif formal, seperti dalam kasus konferensi atau buletin, atau secara spontan dibentuk oleh jaringan sosial tetap yang masuk ke jaringan untuk mengirim dan mengambil pesan yang dipilih serta memiliki pola waktu (baik tertunda atau dalam waktu nyata). Lebih lanjut Rheingold menjelaskan bahwa interaksi di komunitas virtual hampir sama persis dengan kehidupan nyata. Dari penjelasan ini jelas bahwa Rheingold melihat bahwa tidak ada aktifitas yang berbeda baik secara virtual maupun kehidupan nyata.

Kehadiran internet dan keterlibatan masyarakat di internet yang terus semakin naik dari tahun tahun setidaknya dijelaskan Markham (Markham, 2018) dalam tiga bentuk berikut ini: pertama, media atau alat untuk konektivitas jaringan, disebut juga etnografi pada jejaring sosial (Ethnographies of networked sociality). Dipengaruhi oleh Van Dick dalam konsep budaya konektifitas, Castell dalam masyarakat jaringan atau Postill, Pink dalam praktik digital. Dalam sudut pandang ini, internet dilihat sebagai praktik budaya. Memusatkan pada praktik individu dan kelompok, hubungan sosial, dan formasi budaya, yang difasilitasi oleh beberapa aspek dari internet. Fokus pada bagaimana internet sebagai alat atau media komunikasi dan bagaimana konektifitas sosial difasilitasi oleh kapsitas internet.

Kedua, internet sebagai tempat medium, tempat/ruang atau sebuah dunia virtual, dalam pandangan ini etnografi berada dalam lingkungan yang imersif/mendalam (terlibat secara penuh totalitas di internet) atau ethnographies of immersive environments. Banyak dipengaruhi penelitian Tom Boelstorf dengan penelitian pada second life Pada bagian kedua ini karakternnya adalah dunia virtual yang kaya akan objek, melibatkan banyak pengguna, gigih untuk bertahan dalam karakter yang ditentukan meski banyak yang sudah meninggalkan, peserta mungkin bisa menjadi avatar yang direpresentasikan secara tekstual dan juga gambar. Contoh kajiannya pada game digital seperrti Second Life, Farm Ville atau Sims City. Facebook disebut-sebut bisa dikaji dalam konteks ini namun batasnya tidak terlalu jelas. Bentuk ketiga, internet adalah cara hidup, atau etnografi sosial di era dunia digital kontemporer. Pada bagian ketiga ini internet dipandang sebagai media yang merupakan keberlanjutan dan melekat pada ruang sosial dimana terjadi struktur dan relasi sosial yang riil.

Melengkapi pemikiran Rheingold, komunitas virtual adalah kumpulan individu dan / atau mitra bisnis (sehubungan dengan satu atau lebih dari kelompok organik masyarakat), yang berinteraksi karena kepentingan bersama (atau saling melengkapi) dan di mana interaksi tersebut menggunakan bahasa secara umum dan akhirnya kemungkinan munculnya paralanguage umum, dalam kelompok ini ada protokol atau norma bersama sebagai petunjuk yang disepakati bersama. Komunitas ini terwujud setidaknya sebagian dalam ruang bersama digital dan didukung dan / atau dimediasi oleh Internet atau sistem TIK lainnya (yang dapat sinkron, asinkron, atau hibrid) (Agostini \& Mechant, 2019).

Dari pemikiran Ferdinan Tonnies tersebut terjadi pergeseran dari sebuah komunitas karena perkembangan teknologi komunikasi. Virtualitas menjadi dimensi penting pada masyarakat kontemporer karena perubahan radikal dalam berkomunikasi yang dimediasi oleh internet (Castells, 2010). Kehadiran internet bahkan disebut sebagai era mesin kedua setelah revolusi industri dan mengubah bagaimana manusia berkomunikasi (Gallardo, 2019).

\section{Media Sosial dan Komunitas Virtual}

Web 2.0 merupakan medium yang unik karena menimbulkan partisipasi, demokrasi, selain itu juga berkaitan dengan transparasi, dan daya tanggap (Porlezza, 2019). Media sosial bahkan telah terintegrasi menjadi praktik sehari-hari. Meskipun fitur teknologi utama SNS cukup konsisten, namun budaya yang muncul di sekitar SNS beragam (Boyd \& Ellison, 2007).

Media sosial dan ranah virtual secara umum menarik semakin banyak orang, yang sebaliknya berdampak langsung pada perilaku mereka di ranah non virtual. Berkat media sosial, batas antara penyedia informasi dan konsumen informasi sama sekali tidak terlihat. Sementara di sisi lain, fenomena baru ini membuat komunikasi menjadi lebih demokratis dengan memberdayakan masyarakat yang semula pasif (Çela, 2015).

Keterlibatan audiense dalam media diistilahkan oleh Mc Luhan (2013) sebagai hot dan cool media. Istilah ini merujuk pada interaksi dan partisipasi dari audiense dengan media. Hot media adalah media dengan 
partisipasi rendah dari audien, hal ini dikarenakan media itu sendiri sudah banyak informasi, sehingga audiense tidak perlu terlibat untuk melengkapi. Di sisi lain cool media, data atau informasinya sangat rendah sehingga memerlukan audiense untuk terlibat sehingga informasinya menjadi lengkap. Dalam konteks ini, media sosial adalah cool media, media sosial menyediakan fitur atau ruang yang harus diisi oleh audience atau orang-orang yang terlibat di media sosial tersebut melalui akun yang dibuat.

Penelitian mengenai Indonesia (Lim, 2017), lonjakan pengguna media sosial mengubah informasi diproduksi, disebarluaskan, dan didistribusikan dan menjadi praktik Post-truth. Di media sosial, para pemimpin politik menggunakan teknik pencitraan merek komersial melalui jaringan relawan, buzzer, dan selebritas mikro, memenuhi ruang publik dengan pesan emosional yang dirancang untuk menumbuhkan kepercayaan pada merek politik mereka. Media Sosial mendorong kebebasan berekspresi dan bahkan mendorong fragmentasi dalam masyarakat.

Dalam perkembangannya media sosial atau disebut juga dengan Social Networks Sites (SNS) merupakan keseimbangan antara ranah pribadi, komersial dan ruang publik, (Heyman \& Pierson, 2015). Bahkan makna kata 'sosial' dalam media sosial juga menjadi pertanyaan mendasar. Makna 'sosial' dari yang sekarang dibangun oleh media sosial, peran media dalam pembangunan media sosial termasuk apakah individu harus masuk ke online agar dianggap menjadi sosial di era media sosial ini, (Couldry, 2015). Persoalan sosial setidaknya dijelaskan oleh Fuchs (2014a) demikian, bahwa semua sistem komputasi bisa dianggap media sosial karena menyimpan dan menyebarkan pengetahuan manusia yang berasal dari hubungan sosial di masyarakat. Meski begitu bagi Fuchs (2014a) tidak semua sistem komputasi dan aplikasi web mendukung komunikasi langsung antar manusia, di mana setidaknya dua manusia saling bertukar simbol yang ditafsirkan sebagai bermakna.

Media sosial adalah istilah kompleks dengan makna berlapis-lapis. Facebook berisi banyak konten (informasi) dan merupakan alat untuk komunikasi dan untuk pemeliharaan penciptaan komunitas. Facebook seringkali dianggap alat sederhana untuk bekerja kolaboratif, yang melibatkan kognisi, komunikasi dan komunitas, (Fuchs, 2014b). Menurut Fuchs (Fuchs, 2014c), hubungan sosial dalam perspektive ekonomi politik dapat dimediasi melalui kekuatan uang, komoditas, kekuasaan melalui fitur dalam media dan sistem komunikasi modern. Fitur khusus dari media dan sistem komunikasi adalah mengkomunikasikan konten yang dibuat atau dibuat bersama oleh manusia yang disimpan, ditafsirkan, dan ditafsirkan ulang untuk memaknai dunia. Dalam masyarakat modern, sistem budaya tidak terisolasi, tetapi budaya dimediasi oleh uang dalam industri budaya dan kekuasaan dalam komunikasi politik. Sistem budaya memiliki ekonomi dan politiknya sendiri.

Sejak peristiwa Arab Spring pada tahun 2011, penggunaan media sosial sebagai gerakan sosial menjadi inspirasi bagi dunia (Fuchs, 2014b). Penggunaan internet untuk menginformasikan apapun disebut sebagai gerakan, yaitu postmedia. Hal ini disebut pula penggunaan kembali teknologi secara politis, gerakan partisipasi, kampanye yang cukup terbuka bagi siapa saja untuk terlibat dan berpartisipasi, ( Castells, 2015). Media sosial memungkinkan budaya partisipatif menghilangkan sekat kaku antara pengguna dan produsen seperti yang terjadi pada media lama (old media), (Porlezza, 2019). Tidak saja berkembangnya partisipasi politik dan demokrasi, tumbuhnya mikroblog seperti situs jejaring sosial, dan sosial media sebagai model akumulasi modal tidak hanya memberikan peluang baru akan partisipasi ekonomi namun juga budaya, (Fuchs, 2014a).

Internet memfasilitasi ruang publik di era kontemporer, namun ketika menggunakan kata 'publik', maka membayangkan hal-hal yang berkaitan tentang pemikiran dan gagasan pertukaran politik yang terbuka, seperti yang terjadi di agoras Yunani kuno atau balai kota era kolonial (Papacharissi, 2002). Pada masa Yunani kuno, agora adalah pasar, tempat warga bertemu untuk berbicara, bergosip, berdebat, menilai satu sama lain, menemukan titik lemah dalam ide-ide politik dan juga saling debat (Papacharissi, 2002).

Dalam konteks ruang publik atau public sphere, internet dan teknologi memegang kendali untuk kembali menghidupkan kembali public sphere melalui tiga dimensi (Papacharissi, 2002), yaitu: pertama berkaitan dengan ruang penyimpanan berbasis teknologi; kedua, kesetaraan akses informasi sehingga memungkinkan keterwakilan; dan ketiga, berkaitan dengan arus budaya politik yang dibawa oleh teknologi tersebut. Selain menghidupkan kembali dan memenuhi prasyarat tentang ruang publik, media secara umum mempunyai potensi untuk berperan dalam perubahan sosial (Çela, 2015). Dari pengertian tersebut, internet mempunyai potensi besar sebagai medium untuk gerakan sosial untuk perubahan dengan kapasitas dan jangkauannya yang masif. Gerakan sosial yang sebelumnya bersifat sektoral dan lokal dapat menjadi nasional, kemudian bahkan masuk ke tingkatan global dengan kemudahan akses informasi.

\section{Ethnography digital}

Menurut Couldry (2004) landscape media studies setidaknya ada 5 hal: (1) Riset yang berkaitan dengan komunikasi massa di Amerika, dimana ini adalah awal dari kajian media dan disebut juga studi sosial eksperimental, fokus pada efek komunikasi massa dalam skala besar; (2) Kajian kritis yang berbasis dari Marxist 
(critical Marxist) dimana agenda media tidak lepas dari kritik terhadap kapitalisme, dalam kajian komunikasi menjadi kajian ekonomi politik media dan tertarik pada komodifikasi; (3) Analisa Semiotik, dimana berusaha mengadaptasi kajian yang berbasis teks sastra (study literature) ke kajian teks media, focus pada makna dari teks media; (4) Critical research, yang mengkombinasikan study semiotic dan kalayak, proses interpretasi teks dari audience; (5) Penelitian berbasis disiplin ilmu Antropologi pada riset media pada era postmodern. Pada bagian ini media sebagai produksi-sirkulasi dan konsumsi sebagai praktik yang saling berkaitan. Tertarik pada apa yang dilakukan oleh individu dengan media (maka disebut sebagai practice atau praktik). Bukan pada mengoperasikan media sebagai teknologi mesin namun relasi berkesinambungan antar individu-komunitasmasyarakat dengan media.

Pada lanskap kelima yang disajikan Couldry (2004) tersebut kemudian dikembangkan oleh Sarah Pink dan rekan-rekan (2016). Jika interpretive communities (McQuail, 1997) membahas bagaimana audiense secara aktif memaknai isi media berdasarkan latar belakang kehidupannya. Study Ethnografi Digital tidak berhenti pada audiens yang memaknai teks media, namun berinteraksi sirkuler dengan media baik sebagai produsen juga sekaligus konsumen. Pink (2016) menawarkan "Digital Ethnography" sebuah metode untuk bisa memahami dinamika kehidupan (individu dan atau individu sebagai bagian dari komunitas atau masyarakat) di layar digital. Sebelumnya, memahami relung-relung dinamika kehidupan sosial diteliti oleh disiplin ilmu antropologi dan sosiologi. Kedua disiplin ilmu tersebut bekerjasama mempelajari manusia dan kehidupannya. Demikian pula komunikasi mengambil sisi yang belum dibahas dalam kedua kajian tersebut dengan sudut pandang bahwa komunikasi membentuk manusia-masyarakat dan sebaliknya. Oleh karena itu, ketiga disiplin ilmu saling berkelindan untuk menghadirkan pemahaman yang lebih kompleks tentang manusia dan kehidupannya dalam konteks kekinian dimana teknologi komunikasi digital seolah-olah seperti saudara kembar identik dari manusia.

Istilah etnografi digital berasal dari dua kata, yaitu etnografi dan digital. Etnografi adalah sebuah pendekatan yang berusaha untuk mendapatkan pemahaman yang terperinci akan sebuah fenomena. Menekankan pada lokalitas sehingga konteks budaya menjadi karakter yang kuat dalam laporan ethnografi. Peneliti etnografi diharapkan untuk mempunyai keterikatan yang erat dengan subyek study serta bersikap reflektif dan sensitif terhadap perubahan lingkungan dan pada situasi yang kompleks, (Markham, 2018, p. 1133). Meskipun kata 'digital' merujuk pada teknologi sinyal digital atau teknologi komputer, namun dalam konteks kajian Ilmu Komunikasi kata 'digital' merujuk pada mediasi internet dalam komunikasi (lihat dalam Waisbord, 2019).

Ethnografi digital merupakan metode untuk menginvestigasi bagaimana interaksi komunikasi melalui teknologi komunikasi di era kontemporer. Prinsip dasar dalam etnografi (Pink et al., 2016) adalah: (1) multiplicity, yang artinya metode etnografi ini dapat dilakukan dalam banyak cara dan banyak sendi dari dunia digital. Kondisi sarana prasarana yang berbeda beda di tiap daerah menjadikan metode ini diharapkan luwes untuk mendapatkan data; (2) Non-digital centricness, meskipun menggunakan istilah digital, namun Pink menyebutkan bahwa medium digital bukan pusat dari kajian, namun bagian dari elemen-elemen yang saling berkaitan; (3) Opennes, terbuka dengan berbagai kajian dan kemungkinan perspektif; (4) Reflexivity, secara cermat dari berbagai sisi dan mempertimbangkan berbagai konteks dan situasi dalam melaksanakan penelitian; (5) Unorthodox, peneliti diharapkan keluar dari cara-cara tradisional dalam pengumpulkan data dan analisisnya.

Bagi Markham (2018, p. 1133-1134) sikap seorang peneliti ethnogafi tidak berubah ketika mempelajari dunia digital. Hal tersebut dikarenakan digital mentrasformasikan apa yang disebut sebagai sosial dan manusia di dunia. Dari pendapat tersebut melihat bahwa yang ada dalam digital adalah tidak ada bedanya dengan kehidupan riil. Media digital hanya sebagai medium yang melakukan mediasi dari kehidupan sosial manusia. Meski begitu, Markham (2018) mengingatkan bahwa mekanisme kerja dari digital adalah ditentukan secara algoritma sebagai cara kerja dari internet of things, maka etnogarfi adalah seperangkat cara memandang dunia, sekaligus merupakan sikap daripada seperangkat teknik atau metode. Disinilah kemudian kajian ethnografi digital mengajak peneliti untuk memahami berbagai fenomena sosial dengan hadirnya teknologi digital. Layar digital semakin mengaburkan batas-batas yang nyata dan maya termasuk juga wilayah dan budaya. Kita seperti hidup di dua sisi, yaitu sisi riil yang melibatkan seluruh pancainderawi dan sisi maya yang melibatkan hanya indera mata (Pink et al., 2016).

Obyek kajian dalam digital etnografi yang dijelaskan Pink (2016) bisa meliputi bagaimana teknologi komunikasi yang ada di rumah dan digunakan oleh anggota keluarga, relasi yang dibangun melalui medium digital, memahami fenomena sosial dunia di layar digital, mempelajari lokalitas dalam konteks digital hingga penyelenggaran sebuah kegiatan dengan medium digital. Sementara itu metode pengumpulan data pada penelitian etnografi digital ini menurut Pink (2016) sebagai berikut: (a) Hadir di lokasi secara fisik dan berinteraksi dengan partisipan secara tatap muka dan berinteraksi secara terus menerus. (b) Peneliti bisa juga berada di tempat lain dengan mengumpulkan data via skype, streaming, Chat dll. (c) Peneliti bisa secara virtual 
terlibat misalnya masuk dalam grup mailing list, web forum, 3d real game, dll. (d) Ethnographer (peneliti) dan partisipan (subyek penelitian) dapat berada di satu forum maya melalui blogs, sosial media dan video sharing.

Adapun berkaitan dengan data penelitian terdiri dari; (1) artefak digital seperti kata-kata, gambar, file suara, video yang disunting, situs web, bahkan juga wawancara digital serta kerja lapangan secara partisipatif untuk memindahkan persepsi etnografi ke media online Kozinets (2015); (2). Wawancara dengan informan diperlukan untuk mendapatkan data yang lebih akurat. Wawancara dengan informan bisa dilakukan secara langsung atau menggunakan perangkat wawancara secara daring. Wawancara diperlukan mengingat dunia riil atau nyata dan dunia maya atau virtual bukan hal yang berbeda sama sekali. Bagaimanapun juga, 'seseorang' yang berada di dunia maya juga berada di dunia nyata, di satu tempat di bumi dan bahkan jika ia bergerak dengan ponsel pintarnya, atau perangkat fisik lainnya. Hanya saja, masing-masing orang tingkat keterlibatan dalam dunia virtual berbeda-beda tingkatnya. Dunia maya adalah bagian dari dunia nyata dan sebaliknya, (Reed, 2019). (3) Observasi secara langsung untuk dapat memahami konteks sosial budaya dari informan. Menurut Kozinets (2010) komunitas daring tidak virtual. Orang-orang yang kita temui daring tidak virtual. Komunitas online riil dan mempunyai keberadaan nyata.

Langkah Analisa data berdasarkan penjelasan Kozinet (Kozinets, 2010, p. 119) terdiri dari enam langkah yaitu; (1) Coding, yaitu membierikan kode atau kategori dari sumber data daring yang didapatkan melalui data crawling di media daring. Data crawling bisa menggunakan aplikasi salah satunya Nvivo, pengkodean biasanya muncul secara induktif melalui pembacaan data yang cermat, dan tidak memaksakan kategori yang ditentukan; (2) Noting or memoing: membuat catatan kecil atau memo untuk merefleksi data atau memberikan komentar; (3) Abstracting and Comparing Data kemudian disortir dan diidentifikasikan kesamaan, urutan, hubungan, perbedaan. Secara menyeluruh melibatkan kategori konseptual, pola, proses; (4) Checking and Refinement, ke lapangan kembali untuk mengumpulkan data berikutnya serta memberi batasan, memeriksa, dan menyempurnakan pemahaman tentang pola, proses, persamaan, dan perbedaan pada tahapan abstraksi; (5) Generalizing, mengelaborasikan satu kesatuan kecil generalisasi yang mencakup atau menjelaskan konsistensi dalam kumpulan data; (6) Theorizing, dari generalisasi kemudian memformulasikan pengetahuan formal dengan menggunakan konstruksi teori, membangun teori baru berdasarkan analisa data yang relevan dengan kerangka pemikiran. Dalam bukunya terbaru, Kozinet (Kozinets \& Gambetti, 2021) menambahkan fitur immersive atau peneliti mencelupkan dirinya atau terlibat penuh dengan praktik digital dari informan dalam proses investigasi terhadap media sosial atau aplikasi yang digunakan oleh informan.

\section{SIMPULAN DAN SARAN}

Media digital mengikis batasan antar komunikasi interpersonal dan proses yang dimediasi oleh media bahkan akan membawa kita pada bahasan bahwa mediation pada area-area yang secara tradisional tidak mempelajari media (Waisbord, 2019). Diuraikan pula oleh Waisbord, kajian komunikasi pada medium digital mengarah kepada proses, subyek dan teknologi yang berkaitan dengan cara hidup masyarakat kontemporer. Terutama kajiannya berkisar antara proses simbolik, informasi dan koneksi di medium digital. Oleh karena itu, peluang kajian IImu Komunikasi semakin meluas dengan berkembangnya kajian penelitian di ranah digital. Komunitas yang bertumbuh di ruang virtual semakin menarik dikaji dan internet tidak hanya menghubungkan individu, namun lebih dari itu menggerakkan individu yang tersebar dan memungkinkan gerakan sosial yang lebih masif dengan adanya internet dimana komunitas virtual terbentuk. Kajian mengenai komunitas virtual sekaligus merefleksikan kehidupan virtual dan riil tidak ada perbedaan yang mendasar dan menantang kajiankajian yang akan terus berkembang. Kajian komunitas virtual juga menjadi masa depan kajian Ilmu Komunikasi, terutama perkembangan teknologi komunikasi dan semakin masifnya trend perkembangan kajian yang mengarah ke dalam dunia digital.

\section{REFERENSI}

Agostini, S., \& Mechant, P. (2019). Towards a definition of virtual community. Signo y Pensamiento, 38(74). https://doi.org/10.11144/Javeriana.syp38-74.tdvc

Baltezarevic, R., Baltezarevic, B., Kwiatek, P., \& Baltezarevic, V. (2019). The impact of virtual communities on cultural identity. Symposion, 6(1), 7-22. https://doi.org/10.5840/symposion2019611

Bell, D. (1999). The Coming of Post-Industrial Society. Basic Books.

Boyd, D. M., \& Ellison, N. B. (2007). Social network sites: Definition, history, and scholarship. Journal of Computer-Mediated Communication, 13(1), 210-230. https://doi.org/10.1111/j.1083-6101.2007.00393.x

Brint, S. (2001). Gemeinschaft Revisited. Sociological Theory, 19(1), 1-23.

Castells, M. (2010). The Rise of the Network Society second edition. Blackwell.

Çela, E. (2015). Social Media as a New Form of Public Sphere. European Journal of Social Sciences Education and 
Research, 4(1), 195. https://doi.org/10.26417/ejser.v4i1.p195-200

Choi, S., Dukic, Z., \& Hill, A. (2019). Professional networking with Yahoo! Groups: A case of school librarians from international schools in Hong Kong. Journal of Librarianship and Information Science, 51(4), 1077-1090. https://doi.org/10.1177/0961000618763488

Couldry, N. (2004). Theorising media as practice. Social Semiotics, 14(2), $115-132$. https://doi.org/10.1080/1035033042000238295

Couldry, N. (2015). Social Media: Human Life. Social Media and Society, 1(1). https://doi.org/10.1177/2056305115580336

Dalsgaard, S. (2016). The Ethnographic Use of Facebook in Everyday Life. Anthropological Forum, 26(1), 96-114. https://doi.org/10.1080/00664677.2016.1148011

Fuchs, C. (2014a). Digital Labour And Karl Marx. Routledge.

Fuchs, C. (2014b). Social Media A Critical Introduction. Sage.

Fuchs, C. (2014c). Social media and the public sphere. TripleC, 12(1), 57-101. https://doi.org/10.31269/vol12iss1pp57-101

Gallardo, R. (2019). Bringing Communities into the Digital Age. State and Local Government Review, 51(4), 233241. https://doi.org/10.1177/0160323X20926696

Haythornthwaite, C., \& Kendall, L. (2010). Internet and community. American Behavioral Scientist, 53(8), 10831094. https://doi.org/10.1177/0002764209356242

Heryanto, A. (2015). Identitas dan Kenikmatan. PT. Gramedia.

Heyman, R., \& Pierson, J. (2015). Social Media, Delinguistification and Colonization of Lifeworld: Changing Faces of Facebook. Social Media and Society, 1(2). https://doi.org/10.1177/2056305115621933

Hitz, S. R., \& Turoff, M. (1993). The Network Nation: Human Communication via Computer. The MIT Press. https://doi.org/10.1016/0306-4573(95)80054-w

Kemp, S. (2020). Digital 2020: Global Digital Overview 2020. We Are Social. https://wearesocial.com/blog/2020/01/digital-2020-3-8-billion-people-use-social-media

Kozinets, R. V. (2010). Netnography: Doing ethnographic research online. Sage Publications.

Kozinets, R. V., \& Gambetti, R. (2021). Netnography Unlimited. In R. V. Kozinets \& R. Gambetti (Eds.), Netnography Unlimited. https://doi.org/10.4324/9781003001430

Kozinets, R. V. (2015). Netnography Redefined 2nd Edition. Sage.

Lim, M. (2017). Freedom to hate: social media, algorithmic enclaves, and the rise of tribal nationalism in Indonesia. Critical Asian Studies, 49(3), 411-427. https://doi.org/10.1080/14672715.2017.1341188

Lindgren, S. (2017). Digital Media \& Society. Sage Publications Inc.

Manuel Castells. (2015). Networks Of Outrage And Hope: Social Movements In The Internet Age (Second Editions).

Markham, A. N. (2018). Ethnography in the Digital Internet Era: From Fields to Flows, Descriptions to Interventions. In N. K. Denzin \& Y. S. Lincoln (Eds.), The Handbook on Qualitative Research Fifth Edition (5th ed., pp. 1129-1162). Sage.

Maryani, E. (2018). Developing Social Solidarity through Digital Media. Jurnal Komunikasi Ikatan Sarjana Komunikasi Indonesia, 3(1), 12-17. https://doi.org/10.25008/jkiski.v3i1.144

McLuhan, M. (2013). Understanding Media The Extensions of Man. Gingko Press.

McMullan, J. (2020). A new understanding of 'New Media': Online platforms as digital mediums. Convergence, 26(2), 287-301. https://doi.org/10.1177/1354856517738159

McQuail, D. (1997). Audience Analysis. Sage Publisher.

Papacharissi, Z. (2002). The Virtual Sphere. The Information Society Reader, 4(1), 9-27. https://doi.org/10.4324/9780203622278-36

Pink, S., Horts, H., Postill, J., Hjorth, L., Lewis, T., \& Tacchi, J. (2016). Digital Ethnography: Principles \& Practice. (Vol. 8, Issue 1).

Porlezza, C. (2019). From Participatory Culture to Participatory Fatigue: The Problem With the Public. Social Media and Society, 5(3). https://doi.org/10.1177/2056305119856684

Reed, T. V. (2019). Digitized Lives: Culture, Power And Social Change In The Internet Era (second edition). Roulteldge.

Reyes, A. (2019). Virtual communities: Interaction, identity and authority in digital communication. Text and Talk, 39(1), 99-120. https://doi.org/10.1515/text-2018-2020

Rheingold, H. (1994). The virtual community : finding connection in a computerized world. London : Secker \& Warburg.

Servaes, J., \& Hoyng, R. (2017). The tools of social change: A critique of techno-centric development and activism. 
New Media and Society, 19(2), 255-271. https://doi.org/10.1177/1461444815604419

Snyder, H. (2019). Literature review as a research methodology: An overview and guidelines. Journal of Business Research, 104(March), 333-339. https://doi.org/10.1016/j.jbusres.2019.07.039

Tjahyana, L. J. (2021). Studi Netnografi Pola Komunikasi Jaringan Komunitas Cryptocurrency Dogecoin di Twitter. Komunikatif:Jurnal IImiah Komunikasi, 10(1).

Waisbord, S. (2019). Communication A Post-Discipline. Polity Press.

Wong, G., Greenhalgh, T., Westhorp, G., Buckingham, J., \& Pawson, R. (2013). RAMESES publication standards: Meta-narrative reviews. Journal of Advanced Nursing, 69(5), 987-1004. https://doi.org/10.1111/jan.12092

Wong, K., Kwan, R., \& Leung, K. (2011). An exploration of using Facebook to build a virtual community of practice. In K. Wong, R. Kwan, \& K. Leung (Eds.), Hybrid Learning. ICHL 2011. (Vol. 6837, pp. 316-324). Springer, Berlin, Heidelberg. https://doi.org/https://doi.org/10.1007/978-3-642-22763-9_30 